\title{
Recent Update on One-Minute Rainfall Rate Measurements for Microwave Applications in Nigeria
}

\author{
Obiyemi Obiseye O. ${ }^{1}$, Adetan Oluwumi ${ }^{2}$, Ibiyemi Tunji S. ${ }^{3}$ \\ ${ }^{1}$ Department of Electrical and Electronic Engineering, Osun State University, Osogbo, Nigeria \\ ${ }^{2}$ Department of Electrical and Electronics Engineering, Ekiti State University, Ado Ekiti, Nigeria \\ ${ }^{3}$ Department of Electrical and Electronics Engineering, University of Ilorin, Ilorin, Nigeria
}

Email address:

obiseye.obiyemi@uniosun.edu.ng (Obiyemi O. O.), oadetan@gmail.com (Adetan O.), tibiyemi@unilorin.edu.ng (Ibiyemi T. S.)

\section{To cite this article:}

Obiyemi Obiseye O., Adetan Oluwumi, Ibiyemi Tunji S.. Recent Update on One-Minute Rainfall Rate Measurements for Microwave Applications in Nigeria. International Journal of Wireless Communications and Mobile Computing. Vol. 3, No. 3, 2015, pp. 33-39. doi: $10.11648 /$ j.wcmc.20150303.12

\begin{abstract}
Rain rate statistics is required for planning both satellite and terrestrial links, especially in the microwave and millimeter wave bands. Presented in this work is the one-minute rain rate statistics observed over seventeen months using an electronic weather station - Davis Vantage Vue. The installation is at the main campus of Osun State University, Osogbo ( $7^{\circ} 76^{\prime} \mathrm{N}$, $4^{\circ} 60^{\prime} \mathrm{E}$ ), Nigeria. The cumulative rain rate distribution from the measured rain rate is presented alongside predictions by other prominent models. The $\mathrm{R}_{0.01}$ estimate as high as $\sim 120 \mathrm{~mm} / \mathrm{h}$ was obtained from the surface data and subsequently employed in estimating the fade margin over a hypothetical DTH link for the reception of digital television content at $12.245 \mathrm{GHz}$ from EUTELSAT W4/W7. Estimates presented over time percentages ranging between $0.001 \%$ and $1 \%$ are dissimilar. However, their suitability for predicting fade margins over this location could be ascertained via a performance analysis, based on experimental attenuation estimates over the link. The first point rain rate estimate from surface data over Osogbo is reported here and will be very useful for modeling rain attenuation and for planning both terrestrial and earth-space microwave links.
\end{abstract}

Keywords: One-Minute, Rain Rate Statistics, Rain Attenuation, Earth-Space Microwave Links, Point Rain Rate

\section{Introduction}

Rainfall is a major climatic factor and its variability plays several disturbing roles in a number of activities ranging from the transmission of radiowave signals to malaria epidemiology[1]. Among other similar disturbing factors is the hail [2], which is one of the most terrible natural disaster with severe impacts on mankind. For the propagation of radiowave signals however, attenuation due to rain remains a major loss factor required for planning communication systems and it affects applications operating within the microwave (3-30 GHz) and millimeter wave $(30-300 \mathrm{GHz})$ bands, particularly for frequencies beyond $10 \mathrm{GHz}$ [3-5].

Although rain is not the only form of precipitation affecting signal propagation in this band, it accounts for the most severe impairment on transmitted signals than other atmospheric components such as snow, fog, cloud, water vapour, fog, etc. [6-10]. The propagation path, to and from the satellites is actually well-defined through the earth's atmosphere, where the transmitted signal attenuates, scatters, refracts and depolarizes [11]. Most of these propagation mechanisms are however rain induced and more pronounced in tropical climates where rainfall is characterized with high intensity events.

Rainfall data logged in one-minute integration time is considered suitable for monitoring the rapid attenuation fluctuation on the radio path. Earlier studies have presented useful tools for planning satellite and terrestrial microwave links over Nigeria $[12,13]$, the one-minute rain rate estimates presented were deduced mainly from satellite data. Interestingly, a recent comparison by Ojo and Omotosho in [14] however reveals that one-minute rain rate estimates derived from ground data generally performs better than those obtained from satellite data. Since the dearth of ground data, particularly in the required one-minute integration time is still a concern to radio scientists and engineers, the cumulative rain rate distribution derived from ground-based observations in Osogbo will therefore provide a useful update. 
Moreover, several rain rate models have been developed from long term precipitation statistics over different locations. Prominent among others are those developed from data collected in Brazzaville, Congo [15], those developed from a data bank containing 290 data sets for 30 countries [16], those predicting rain rain rate based on local climatological data available over any location [17], and the global ITU-R rain rate model as recommended in [18]. These models have been useful for the prediction of the cumulative rain rate distribution for selected locations in Nigeria [13, 19-21]. The radio climatological data required to ascertain their suitability for predictions over Nigeria is still sparse. Investigations on the performance of such models over some tropical sites however reveals that the rainfall rates derived using such models are either overestimated or underestimated [19, 21]. However, the implication is as stated in [22], where over-prediction is considered to account for designs that are less effective in cost, while under-prediction limits reliability of the link. There is the need to update radio-climatological database for accurate propagation design purposes. This can be achieved through a deliberate and aggressive precipitation measurement campaign, using a network of rain gauge installations across Nigeria.

Besides, the knowledge of surface precipitation data would enhance reliable link planning, required to meet the increasing demand for bandwidth and multimedia services. Likewise, communication satellites retain backhaul obligations for broadband internet service provision and digital DTH distribution. The detailed estimate of the fade margins required to maintain the high quality content also depends on the local rain rate date. These satellites offer trans-border services through its large footprint (typically delivering contents or services across rural, sun-urban and urban settings). The apparent digital divide can therefore be minimized through a deliberate effort to provide reliable services using satellite. This also dictates the need for improved availability, especially for mission critical applications, where little or no downtime can be tolerated.

Generally, the attenuation induced by rain $A(d B)$ is estimated from the knowledge of the rainfall rate $\mathrm{R}(\mathrm{mm} / \mathrm{h})$, which is expressed as [6]:

$$
A=a R^{b} l
$$

where $a$ and $b$ are coefficients depending on the Drop Size Distribution (DSD), frequency, elevation angle, temperature of the raindrops and polarization of the radiowave, while 1 is the equivalent path length of the rainy region, and is usually set to be about $5 \mathrm{~km}$ on high elevation angle on the earth-space link [23, 24].

Since the accurate prediction of rainfall attenuation depends on the knowledge of the long-term local precipitation data over a particular area, the rain gauge installation at Osun State University, Osogbo is an addition to the South-western precipitation measurement network [4, 24-27] for propagation studies in Nigeria. Due to the short integration time requirement for radio propagation purposes, the daily precipitation measurement at the Osogbo Aerodrome has not been directly useful in this regard.

The analysis of the ground-based one-minute rain rate measurement at Osun State University, Osogbo, South-West Nigeria is presented in this work. The cumulative rain rate estimates derived from the seventeen-month observation is a useful update to the precipitation database required for radio-climatic studies and for estimating rain fade in the design of satellite and terrestrial microwave links.

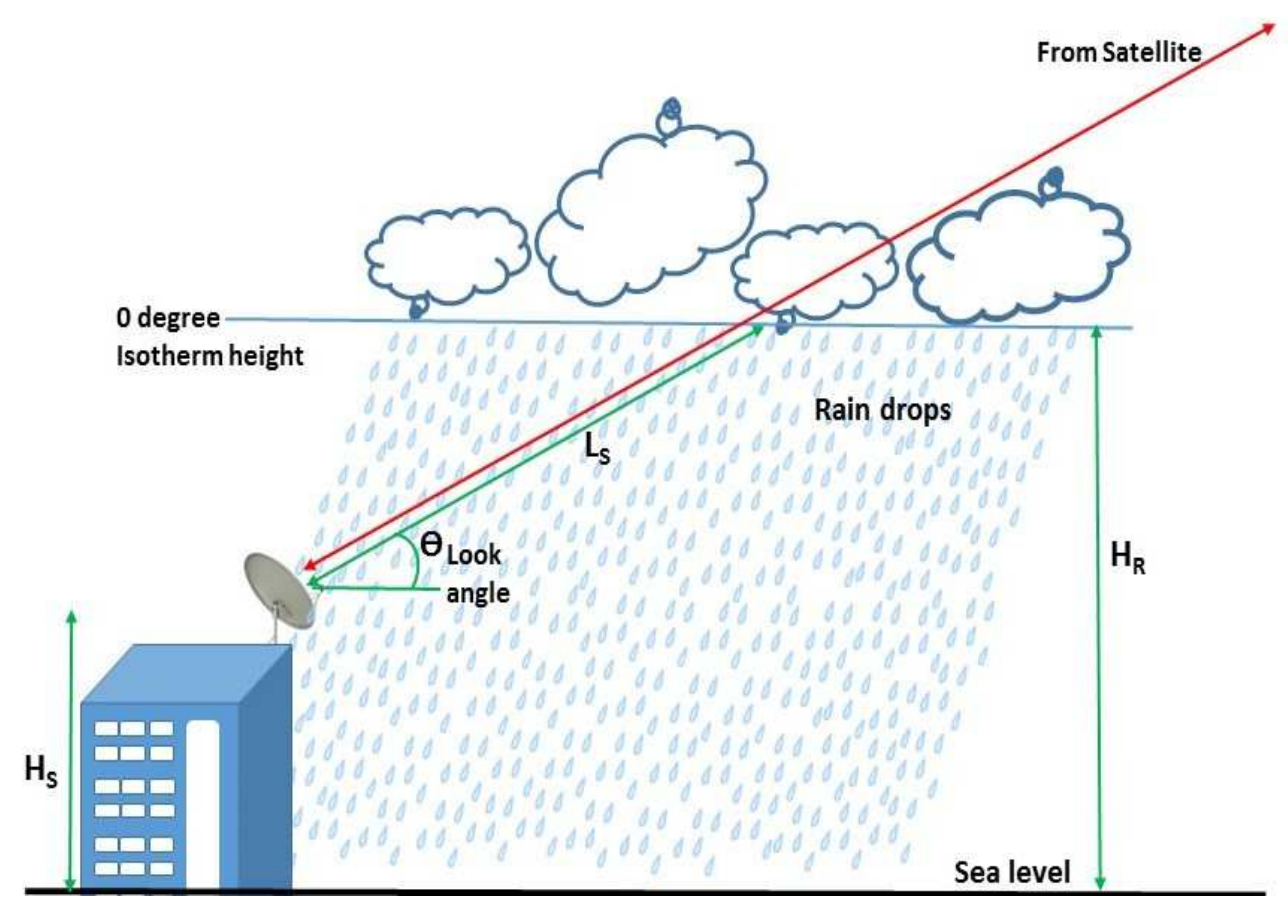

Figure 1. Geometry of a typical DTH link. 


\section{Rain Rate and Rain Attenuation Prediction Techniques}

Several techniques have been employed for the prediction of rain rate over the years. They become very useful, particularly in locations where precipitation data are not available in the preferred short integration time format. Prominent among others are techniques developed by Moupfouma and Martins [15], Rice and Holmberg[17], Ito and Hosoya [16] and the ITU-R [18]. Estimates based on these techniques are compared with the measured rain rate statistics using the cumulative distributions predicted for Osogbo, Osun State.

The point rain rate estimate derived for Osogbo will remain useful for planning over terrestrial and satellite microwave and millimeter wave links, especially in other locations within the $\mathrm{P}$ zone of the rain climatic region, where such data do not exist. This knowledge is also employed for estimating the attenuation induced by rain on a typical Direct-To-Home (DTH) link for reception of digital television (TV) content via EUTELSAT W4/W7, geostationary at longitude 360 East. The selected models are the ITU-R model [6], Garcia model, Svjatogor model, Bryant model and the Australian model. Details of these models can be found in [28]. It is also important to investigate the suitability of these models.
However, this will require an experimental data obtained over a period during - typically a year or more, at the earth station of a practical DTH link. The geometry of a typical DTH link is shown in Figure 1.

\section{Experimental Site and Measurement}

Rain gauge represents the most common equipment for the acquisition of surface precipitation data over a site. The data used in this work was obtained from a Davis Vantage Vue weather station, manufactured by Davis Instruments, Hayward, California, USA. The installation is at the rooftop of the College of Science, Engineering and Technology (CSET) building (about $360 \mathrm{~m}$ above sea level) at the main campus of Osun state University, Osogbo, Nigeria (7.760 N and 4.600 E). The weather station is a tipping spoon type and also measures and records data for other quantities such as temperature, relative humidity, wind speed and direction, all combined in the Integrated Sensor Suite (ISS). A sensor interface module (SIM) collects outside data from the ISS and transmits the data to a Vantage Vue console via low power radio at a frequency range of $868.0-868.6 \mathrm{MHz}$ with a maximum line of sight distance of $300 \mathrm{~m}$ for reliable communication between the outdoor ISS and the indoor console. Figure 2 shows the measurement site in Osun State, South-Western Nigeria.

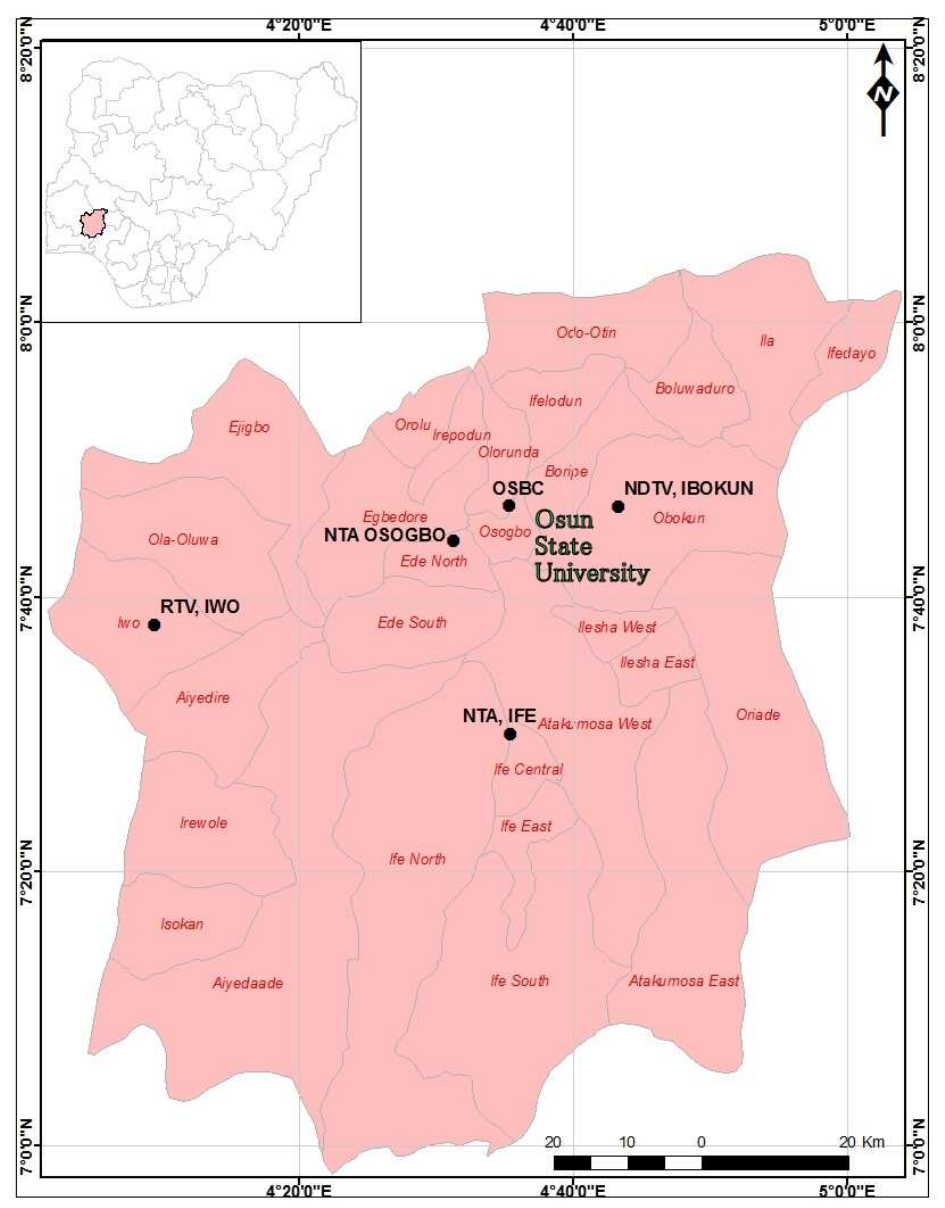

Figure 2. Map of Osun state showing the experimental site. 


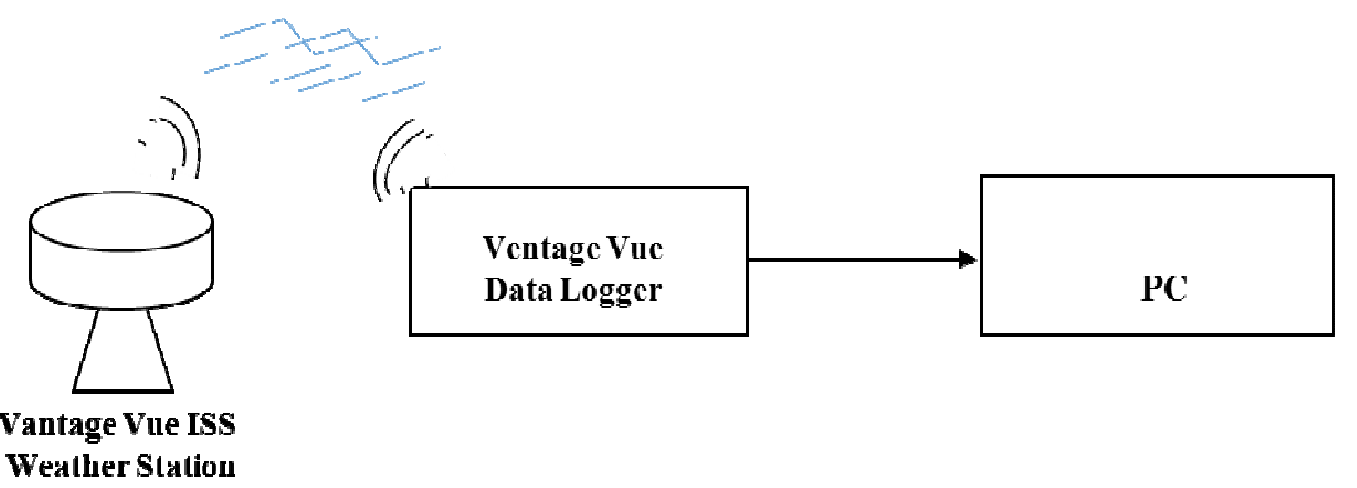

Figure 3. Block diagram of the measurement setup at Osun State University, Osogbo.

The accuracy of the gauge is $\pm 1 \%$ at 1 litter/h with a measuring range of a minimum of $2 \mathrm{~mm} / \mathrm{h}$ to a $400 \mathrm{~mm} / \mathrm{h}$. The gauge is accurate to within $2 \%$ up to $250 \mathrm{~mm} / \mathrm{h}$. Rainfall up to $400 \mathrm{~mm} / \mathrm{h}$ is measured with the resolution of $0.2 \mathrm{~mm}$. The data logger scans the data at every one second intervals and integrated over one-minute interval. The availability of the gauge is about $99.2 \%$. And the $0.8 \%$ unavailability is due to system maintenance and system shutdown as a result of power drain. The console incorporates a Weatherlink software and USB data logger that is synchronized with the personal computer, hence facilitating improved weather monitoring capabilities and a continuous data logging. The block diagram of the measurement setup is as shown in Figure 3.

\section{Results and Discussion}

The one-minute rain rate data collected using the Davis Vantage Vue weather station for the period between March 2013 and July 2014 was sorted and analyzed to provide the precipitation data required for rain attenuation prediction over Osogbo. Statistical analysis of the 17-month precipitation data is also presented here. The parameters extracted from the weather station include; rainfall rate for each month, number of one-minute rain rate recorded throughout the period and a number of other parameters.

Table 1. Precipitation statistics for the 17-month observation.

\begin{tabular}{llllll}
\hline Month & $\begin{array}{l}\text { Minimum rain rate } \\
(\mathbf{m m} / \mathbf{h})\end{array}$ & $\begin{array}{l}\text { Maximum rain rate } \\
(\mathbf{m m} / \mathbf{h})\end{array}$ & $\begin{array}{l}\text { Total rain rate } \\
(\mathbf{m m} / \mathbf{h})\end{array}$ & $\begin{array}{l}\text { Number of rain } \\
\text { duration }\end{array}$ & $\begin{array}{l}\text { Number of one-minute rain rate } \\
\text { recorded per month }\end{array}$ \\
\hline March, 13 & 0.8 & 57.4 & 569.8 & 72 & 4914 \\
April, 13 & 0.8 & 256 & 11759 & 940 & 18013 \\
May, 13 & 0.8 & 122.9 & 5601.8 & 406 & 16768 \\
June, 13 & 0.2 & 94.5 & 1618.7 & 303 & 20498 \\
July, 13 & 0.8 & 286.6 & 4066.5 & 509 & 31470 \\
August, 13 & 1.0 & 27.9 & 317.7 & 90 & 15633 \\
September,13 & 1.0 & 87.6 & 7666 & 1041 & 28778 \\
October, 13 & 0.8 & 281 & 5062 & 450 & 27894 \\
November, 13 & 1.0 & 115.3 & 816 & 33 & 25994 \\
April, 14 & 1.0 & 18 & 240.1 & 71 & 10520 \\
May, 14 & 1.0 & 124 & 5401.3 & 1000 & 18820 \\
June, 14 & 1.0 & 98.3 & 4434.2 & 283 & 11732 \\
July, 14 & 1.0 & 190 & 5109.1 & 429 \\
Total & 11.2 & 1759.5 & 52662.2 & 5627 \\
\hline
\end{tabular}

Table 1 shows the precipitation statistics for the observation period. The highest rainfall intensity was observed in the month of July, 2013 with an intensity of $286.6 \mathrm{~mm} / \mathrm{h}$, followed by October, 2013 with $281 \mathrm{~mm} / \mathrm{h}$. Usually, Rainfall in Nigeria is usually observed between the months of March and October. The minimum total rainfall intensity was recorded in November of 2013, while the highest was recorded in September, 2013. The total rain rate in August is low due to the "August break", which typically lasts for about 3 weeks.

The total number of one-minute rain rate recorded per month varies from 4914 to 31470 . The lowest number was observed in March, 2013 with a total record of 4914, while July 2013 is said to the have the highest number with a total number of 31470 one-minute rain rate recordings. The total record taken for the whole 17-month observation is 239894 .

Table 2 shows the number of days when rain accumulation is either equal to or less than $0.2 \mathrm{~mm}$. Stratiform rain type of longer duration is witnessed when rainfall accumulation is less than or equal to $0.2 \mathrm{~mm}$, much of these are observed in July and October 2013. On the other hand, when rainfall accumulation is greater than $0.2 \mathrm{~mm}$, the convective rain type is said to be in occurrence. The month of April, 2013 and June, 2014 recorded a number of the convective rain type occurrence with 21 and 17 days respectively.

Figure 4 presents the comparison of cumulative distribution of the predicted rain rate and the measured rain rate. It is observed that the cumulative rain rate statistics is underestimated by the ITU-R prediction and this is 
pronounced at lower time percentages $(0.001-0.1 \%)$. Apart from the sharp contrast observed below $0.01 \%$ of the time, predictions based on other selected models show better agreement with the measured data. The measured rainfall rates for the $0.01 \%$ is $120 \mathrm{~mm} / \mathrm{h}$. Rain rate estimates for the same time percentage for the ITU-R, MOUPFOUMA, RH and KITAMI models are $55 \mathrm{~mm} / \mathrm{h}, 103.7 \mathrm{~mm} / \mathrm{h}, 113.2 \mathrm{~mm} / \mathrm{h}$ and $120 \mathrm{~mm} / \mathrm{h}$ respectively.

Table 1. Days one-minute accumulation exceeds or equal to $0.2 \mathrm{~mm}$.

\begin{tabular}{lll}
\hline Month & $\begin{array}{l}\text { Days one-minute acc. } \\
\text { exceeds } 0.2 \mathbf{m m}\end{array}$ & $\begin{array}{l}\text { Days 1-minute acc. } \\
\text { tips equals 0.2 mm }\end{array}$ \\
\hline March, 13 & 6 & 15 \\
April, 13 & 21 & 4 \\
May, 13 & 4 & 9 \\
June, 13 & 11 & 4 \\
July, 13 & 5 & 21 \\
August, 13 & 2 & 13 \\
September, 13 & 8 & 12 \\
October, 13 & 8 & 24 \\
November, 13 & 2 & 11 \\
April, 14 & 2 & 18 \\
May, 14 & 15 & 13 \\
June, 14 & 17 & 6 \\
July, 14 & 4 & 15 \\
Total & 105 & 165 \\
\hline
\end{tabular}

This result agrees with the estimate for Osogbo based on the
ITU-R rain climatic zone [29], which groups Osogbo with other locations in the South-western part of Nigeria in the $\mathrm{P}$ zone. However, measurement is still ongoing at this station and the result will be validated from time to time.

Figure 5 shows the cumulative distributions of the rain attenuation predicted using the surface rainfall data for all the models selected. This presents the one-to-one hypothetical behavior of the rain attenuation models at varying percentages of the time and under the same design condition. 52.50 was maintained as the antenna look angle for typical reception of digital television content at $12.245 \mathrm{GHz}$ via EUTELSAT W4/W7 satellite, which is geostationary at longitude 360 East. The attenuation induced by rain at $0.01 \%$ of the time is 16.2 $\mathrm{dB}, 14.75 \mathrm{~dB}, 14.56 \mathrm{~dB}, 10.61 \mathrm{~dB}$ and $5.46 \mathrm{~dB}$ respectively for ITU, Garcia, Australian, Svjatogor and Bryant models.

At lower time percentage, $0.001 \%$ of the time, the Garcia model presents the highest estimate of $29.8 \mathrm{~dB}$. The Bryant model still retains the lowest estimate of $12.24 \mathrm{~dB}$, while the Australian, ITU-R and Svjatogor models predicted $29.4 \mathrm{~dB}$, $25.2 \mathrm{~dB}$ and $22.2 \mathrm{~dB}$ respectively.

The models show dissimilar estimates at lower percentages of the time and it is still difficult to present the model that outperforms all others in this scenario. Their performance can be better ascertained with experimental data obtained over a practical link.

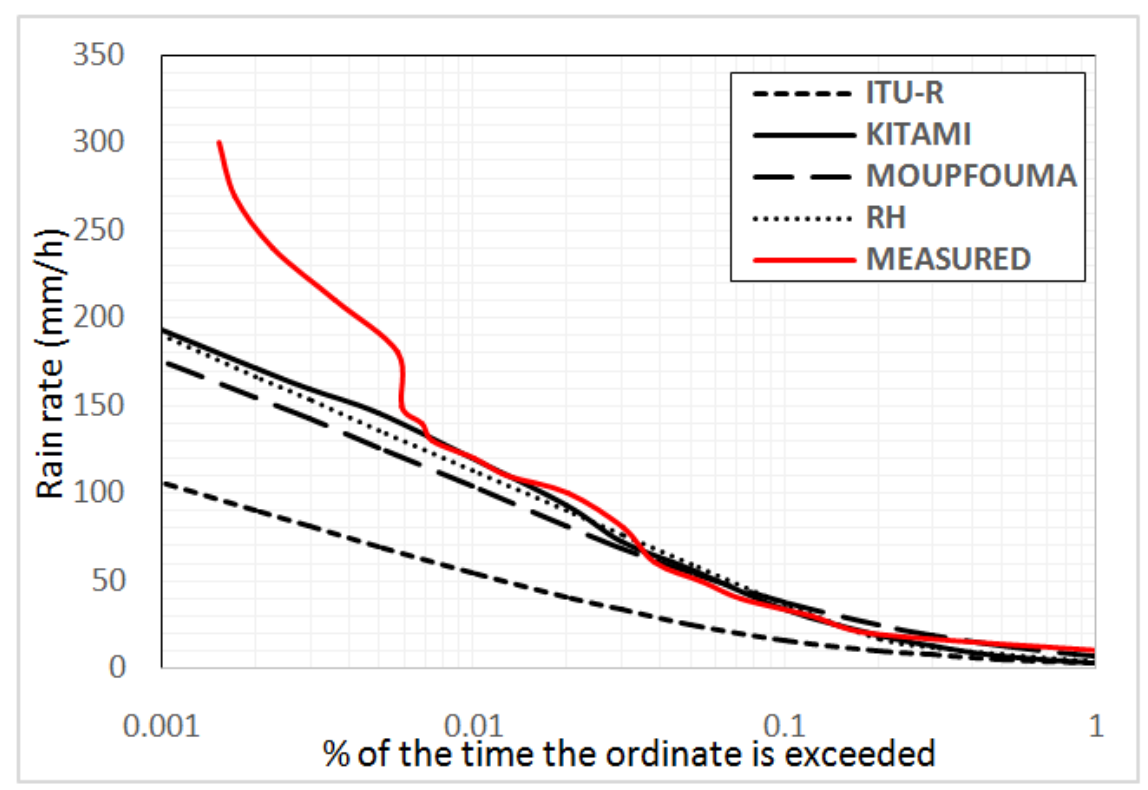

Figure 4. Cumulative rain rate distribution over the observation period. 


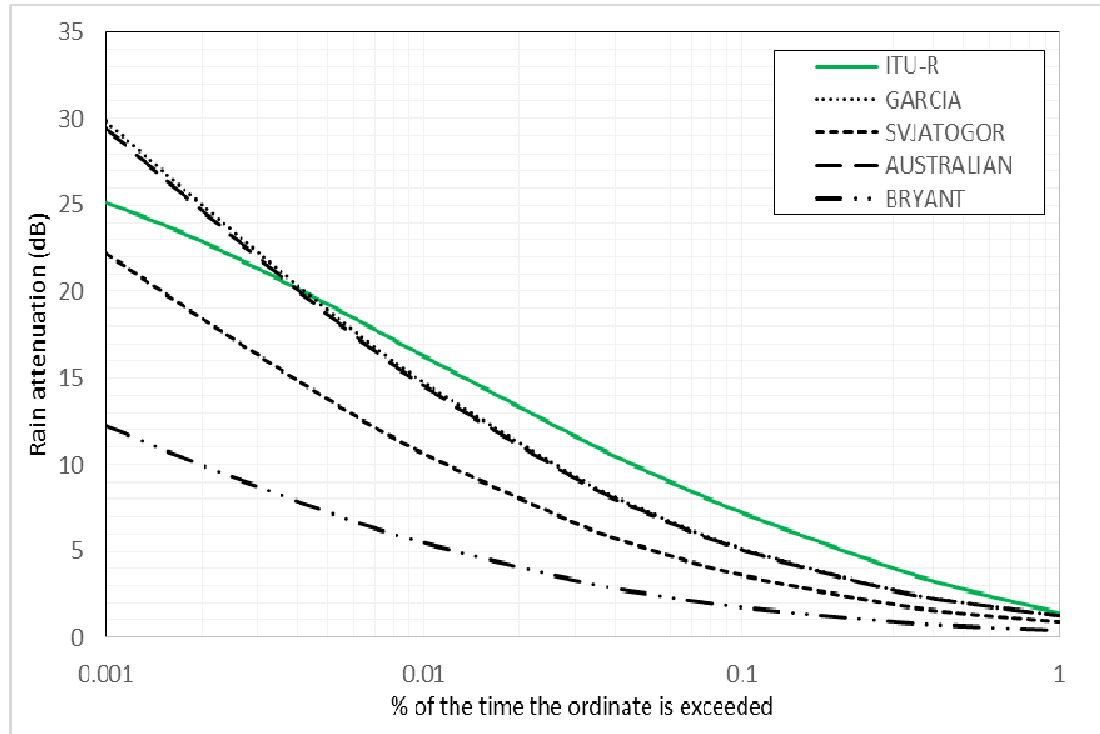

Figure 5. Rain attenuation predicted for a typical DTH link (12.245 GHz, EUTELSAT 36B).

\section{Conclusions}

In the quest to reduce the problem of rainfall attenuation and to update global precipitation database for radio-climatic and other applications, the first point rain rate estimate from surface data collected in Osogbo is presented here and will be very useful for modeling rain attenuation and for planning both terrestrial and earth space microwave links. The rainfall rate exceeded at $0.01 \%$ of the time is estimated as $120 \mathrm{~mm} / \mathrm{h}$ for the 17-month observation, and this estimate was employed in predicting the attenuation induced by rain over a hypothetical DTH link for digital television reception at 12.245 GHz. Estimates presented over time percentages ranging between $0.001 \%$ and $1 \%$ are dissimilar. However, their suitability for predicting fade margins over this location could be ascertained via a performance analysis, based on experimental attenuation estimates over the link. Interestingly, precipitation measurements is ongoing at this station and the result presented is a useful tool for national and regional communication link designs.

\section{References}

[1] A. W. Kassa and B. B. Beyene, "Climate variability and malaria transmission - Fogera district, Ethiopia, 2003-2011," Science Journal of Public Health, vol. 2, pp. 234-237, 2014.

[2] I. S. Akhmedovic, "The unique method to prevent hail," Science Discovery, vol. 2, pp. 43-46, 2014.

[3] J. Chebil and A. Rahman, "Development of 1 min rain rate contour maps for microwave applications in Malaysian Peninsula," Electronics Letters, vol. 35, pp. 1772-1774, 1999.

[4] G. O. Ajayi and E. B. C. Ofoche, "Some tropical rainfall rate characteristics at Ile-Ife for microwave and millimeter wave applications," Journal of Applied Meteorology, vol. 23, pp. $562-567,1984$.
[5] R. K. Crane, "Prediction of Attenuation by Rain," IEEE Transactions on Communications, vol. 28, pp. 1717-1733, 1980.

[6] I. T. U. Radiowave Propagation Series, "Propagation Data and Prediction Methods Required for the Design of Earth-Space Telecommunication Systems," in Recommendation ITU-R P.618-10, ed: I TU-R, Geneva, 2009.

[7] J. M. Garcia-Rubia, J. M. Riera, P. Garcia-del-Pino, and A. Benarroch, "Propagation in the Ka Band: Experimental Characterization for Satellite Applications," IEEE Antennas and Propagation Magazine, vol. 52, pp. 65-76, 2011.

[8] R. K. Crane, Electromagnetic Wave Propagation Through Rain: John Wiley, New York, 1996.

[9] H. Y. Chen and D. P. Lin, "Volume Integral Equation Solution of Microwave Absorption and Scattering by Raindrops," in Antennas and Propagation Society International Symposium, IEEE, Orlando, FL, USA 1999, pp. 2676-2679.

[10] J. S. Ojo, M. O. Ajewole, and S. K. Sarkar, "Rain rate and rain attenuation prediction for satellite communication in $\mathrm{Ku}$ and Ka bands over Nigeria," Progress In Electromagnetics Research B, vol. 5, pp. 207-223, 2008.

[11] A. Pawlina-Bonati, "Essential Knowledge of Rain Structure for Radio Applications Based on available Data and Models," in Proceedings of the Third Regional Workshop on Radio Communication in Africa, Botswana Conference and Exhibition Centre, 1999, pp. 96 - 106.

[12] T. V. Omotosho and C. O. Oluwafemi, "One-minute rain rate distribution in Nigeria derived from TRMM satellite data," Journal of Atmospheric and Solar-Terrestrial Physics, vol. 71, pp. 625-633, 4// 2009.

[13] J. S. Ojo, M. O. Ajewole, and L. D. Emiliani, "One-minute rain-rate contour maps for microwave-communication-system planning in a tropical country: Nigeria," Antennas and Propagation Magazine, IEEE, vol. 51, pp. 82-89, 2009.

[14] J. S. Ojo and T. V. Omotosho, "Comparison of 1-minute rain rate derived from TRMM satellite data and raingauge data for microwave applications in Nigeria," Journal of Atmospheric and Solar-Terrestrial Physics, vol. 102, pp. 17-25, 2013. 
[15] F. Moupfouma and L. Martin, "Modeling of the Rainfall Rate Cumulative Distribution for the Design of Satellite and Terrestrial Communication Systems," International Journal of Satellite Communications, vol. 13, pp. 105-115, Mar-Apr 1995.

[16] C. Ito and Y. Hosaya, "Worldwide 1-min. rain rate distribution prediction method which uses thunderstorm ratio as regional climatic parameter," Electronic Letters, vol. 35, pp. 1585-1587, 1999.

[17] P. Rice and N. Holmberg, "Cumulative time statistics of surface-point rainfall rates," Communications, IEEE Transactions on, vol. 21, pp. 1131-1136, 1973.

[18] I. T. U. Radiowave Propagation Series, "Characteristics of precipitation for propagation modelling," in Recommendation ITU-R P.837-6, ed: ITU-R, Geneva, 2012.

[19] J. S. Ojo and S. E. Falodun, "NECOP Propagation Experiment: Rain-Rate Distributions Observations and Prediction Model Comparisons," International Journal of Antennas and Propagation, 2012.

[20] O. O. Obiyemi, J. S. Ojo, and T. S. Ibiyemi, "Performance Analysis of Rain Rate Models for Microwave Propagation Designs Over Tropical Climate," Progress In Electromagnetics Research M, vol. 39, pp. 115-122, 2014.

[21] T. S. Ibiyemi, M. O. Ajewole, J. S. Ojo, and O. O. Obiyemi, "Rain rate and rain attenuation prediction with experimental rain attenuation efforts in south-western Nigeria," 20th Telecommunications Forum (TELFOR), pp. 327-329, 20-22nd, November 2012.

[22] R. I. Olsen, "Radioclimatological Modeling of Propagation Effects in Clear-Air and Precipitation Conditions: Recent Advances and Future Directions," in Third Regional Workshop on Radio Communication in Africa (Radio Africa '99), Gborone- Botswana, 1999, pp. 81 - 87.
[23] I. T. U. Radiowave Propagation Series, "Specific attenuation model for rain for use in prediction methods," in Recommendation ITU-R P.838-3, ed: ITU-R, Geneva, 2005.

[24] T. V. Omotosho, A. A. Willoughby, M. L. Akinyemi, J. S. Mandeep, and M. Abdullah, "One year results of one minute rainfall rate measurement at Covenant University, Southwest Nigeria," in International Conference on Space Science and Communication (IconSpace), 2013 IEEE Melaka 2013, pp. 98-101.

[25] J. S. Ojo and E. O. Olurotimi, "Tropical Rainfall Structure Characterization over Two Stations in Southwestern Nigeria for Radiowave Propagation Purposes," Journal of Emerging Trends in Engineering and Applied Sciences, vol. 5, pp. 116-122, 2014.

[26] F. A. Semire, R. Mohd-Mokhtar, T. V. Omotosho, I. Widad, N. Mohamad, and J. Mandeep, "Analysis of Cumulative Distribution Function of 2-year Rainfall Measurements in Ogbomoso, Nigeria," International Journal of Applied Science and Engineering, vol. 10, pp. 171-179, 2012.

[27] O. O. Obiyemi, T. J. Afullo, and T. S. Ibiyemi, "Equivalent 1-Minute Rain Rate Statistics and Seasonal Fade Estimates in the Microwave Band for South-Western Nigeria," Int. Journal of Scientific \& Engineering Research, vol. 5, pp. 239-244, 2014.

[28] B. Arbesser-Rastburg, E.-e. Tos-eep, and K. N.-A. Noordwijk, "Radiowave propagation modelling for new satcom services at Ku-band and above," COST 255, 2002.

[29] I. T. U. Radiowave Propagation Series, "Characteristics of precipitation for propagation modelling," in Recommendation ITU-R P.837-1, ed: ITU-R, Geneva, 1994. 